\title{
Child Marriage and Physical Violence: Results from a Nationally Representative Study in Nepal
}

\begin{abstract}
Child marriage is a significant public health concern especially in developing countries. This study examines the prevalence and factors influencing the physical violence among married women in Nepal. More specifically, this paper aims to investigate whether child marriage has an effect on married women's experience of physical violence by their husbands. Data were drawn from the Nepal Demographic and Health Survey, 2016, involving currently married women aged 15-49 years who had participated in the domestic violence module $(n=3447)$. Weighted percentages were calculated to examine the age at marriage for experiencing physical violence from their husband. A multivariate logistic regression model was used to assess risk factors of physical violence due to child and early marriage. After controlling individual, household and community characteristics, this study found that lower age at marriage had increased odds of women experiencing physical violence by their husband. It is found that women who got married at less than 15 years, 15-17 years, 18 -19 years were 2.3 times (adjusted $O R=2.33$ ), 1.68 times (adjusted $O R=1.68$ ) and 1.64 times (adjusted $O R=1.64$ ) respectively more likely to experience violence by their husbands than those who got married at the age of 20 years or later. Child and early marriage puts women at increased risk of physical and sexual violence. Government agencies need to strictly enforce existing law on the minimum age at marriage to reduce violence from their husband and increase quality of life of women and family.
\end{abstract}

Ramesh Adhikari, PhD*

Keywords: child marriage, physical violence, husband, women's autonomy

\section{Introduction}

Child marriage is a significant public health concern for girls, families and their communities. Child marriage is defined as a formal marriage or informal union before the age of 18 (UNICEF, 2014). The largest total number of child brides resides in South Asia (Parsons et al, 2015). Data indicate that 1 in 3 women currently aged 20-24 in the developing countries has married before the age of 18 (UNFPA, 2014). The Sustainable Development Goals (SDGs) target 5.3 aims to eliminate all harmful practices, such as child, early and forced marriage (NPC, 2015).

Child marriage has been illegal in Nepal since 1963. So, a arranging a child marriage or marrying a child is also punishable by law. The legal age of marriage is 20 years for both men and women, according to the Nepalese Country Code. However, it still remains a serious social ill practice in Nepal. Study showed that two in five girls (40\%) aged 20-24 got married before

${ }^{*}$ Reader, Mahendra Campus, Tahachal
18 years and seven percent got married before the age of 15 (MoH, New ERA and ICF, 2017). Child marriage is highly prevalent in the Terai region bordering India, as well as in the Far and Mid-Western regions. The tendency of child marriage is decreasing in Nepal, but it is still very high compared to the situation in other countries.

Child marriage denies the young an opportunity to grow and empower themselves. Child marriage undermines efforts to improve child health and survival, to reduce maternal mortality, and to achieve universal primary education. On the other hand, it increases exposure to sexually transmitted infections (STIs), including HIV (Nour, 2006; Clark, 2004; Glynn et al., 2001). In addition to health concerns, child marriage introduces other pernicious effects. Marriage often means the end of a girl's education and reduction in other opportunities. Although the practice affects both sexes, girls are usually more affected than boys (Erulkar, 2013). Studies in India (Santhya et al., 
2006; ICRW 2011), Nepal (Bajracharya and Amin, 2010), and Bangladesh (ICRW and Plan, 2013) find that girls from poor households are significantly more likely to marry early. Child marriage leads to pregnancy and childbirth before they have reached physical maturity, a circumstance that often produces serious physical trauma, psychological disturbance, and sometimes lifelong physical and/or emotional incapacities. A study found that ninety percent of early first births happen within the context of child marriage, and girls between 15 and 19 years of age are far more likely to experience complications during pregnancy and childbirth than those over twenty (Erulkar, 2013; Murphy and Carr, 2007).

Gender-based violence takes many forms and can occur throughout the life cycle. Child marriage is, in itself, recognized as a form of gender-based violence by the United Nations and many governments, and the practice can also perpetuate other forms of gender-based violence. Violence in childhood and later can also affect girls' and women's abilities to fully benefit from and participate in schooling and employment, thus constraining their lifetime opportunities for education and career. Violence not only affects the girls and women experiencing it and their families, but also can spiral across generations (Solotaroff and Pande, 2014). Studies conducted in India, Bangladesh and Pakistan showed that child marriage and early marriage are known risk factors for intimate partner violence (Nasrullah et al., 2014; Oshiro et al., 2011; Rahman et al., 2014; Raj et al., 2010; Santhya, 2011; Speizer and Pearson, 2011). Studies found that women who have experienced violence are significantly more likely to experience problems such as fear of intimacy, lack of sexual pleasure, and anxiety about sexual performance than other women (De Visser et al., 2007; Najman et al., 2005). The prevalence of STI and HIV/AIDS has been found high among the women who have faced violence (De Visser et al., 2007; Campbell et al., 2008). Women who have experienced violence are more likely to smoke cigarettes and indulge in excessive alcohol consumption (Maharaj et al., 2007; Hughes et al., 2001) and have poorer physical health (Campbell, 2002) and poorer psychological health (De Visser et al., 2007, Maharaj et al., 2007).

This study is an attempt to examine the prevalence and factors influencing the violence among married women in Nepal. More specifically, this paper aims to investigate whether child marriage has an impact on married women's experience of physical violence by their husband. In addition, this paper also aims to fill the knowledge gap in the literature regarding child marriage and violence. The finding of this paper also helps reproductive health program planners and policy makers to understand the various factors influencing gender based violence so as to implement reproductive health programmes that increase women's age at marriage and decrease violence by their husband. Although a few studies on child marriage and its effect in experiencing violence do exist, this type of research has not yet been undertaken in Nepal as far as our knowledge.

\section{Methods}

This paper uses secondary data from the Nepal Demographic and Health Survey (NDHS), 2016, a nationally representative sample survey. The primary objective of the 2016 NDHS is to provide up-to-date estimates of basic demographic and health indicators. The NDHS provides a comprehensive overview of population, maternal, and child health issues in Nepal. The study protocol was approved by the Nepal Health Research Council and the ICF Macro Institutional Review Board in Calverton, Maryland, USA. All respondents had provided verbal informed consent to be interviewed prior to data collection. The survey was carried 
out under the aegis of the Population Division of the Ministry of Health and Population. For this study, we used publicly available dataset from the website of DHS (MoH, 2017).

Interviews were completed for 12,862 women of reproductive age. The analysis of this paper is confined to the currently married women aged 15-49 years who had participated in the domestic violence module $(n=3447)$. Details of the methodology and questionnaire used in the survey can be found in the published report of Nepal Demographic and Health Survey $(\mathrm{MoH}$ et al., 2017).

The dependent variable of this study is the experience of physical violence, measured in terms of whether or not women had experience of physical violence in their life time by their husband. The main independent variable is 'age at marriage'. It is categorized into four categories i.e. below 15 years, 1517 years, $18-19$ years; and 20 years or above. Individual characteristics of women, socioeconomic characteristics of the household and community level characteristics were used as control variables in this study. Physical violence was measured by asking women if their husband ever did: push you, shake you, or throw something at you; slap you; twist your arm or pull your hair; punch you with his/her fist or with something that could hurt you; kick you, drag you, or beat you up; try to choke you or burn you on purpose; or threaten or attack you with a knife, gun, or any other weapon.

Weighted percentages were calculated to examine the age at marriage for experiencing physical and sexual violence from their husband. A multivariate logistic regression model was used to assess risk factors of physical and sexual violence due to child marriage. Prior to the multivariate analysis, multi-colinearity between the variables was assessed. The analysis found that age of the women and number of children born were highly correlated $(\mathrm{r}=0.67)$. Therefore age of women was removed from the logistic regression model.

Two logistic regression models have been used in the analysis. The first model contained the variable related to the age at marriage as the main independent variable. In the second model, individual characteristics of women (age, education, women's autonomy, working status), household characteristics (ethnicity, religion, wealth status) and community characteristics (province and place of residence) were added to examine the net effect of the age at marriage on experience of physical violence by their husband after controlling the individual, family and community characteristics. The Statistical Package for Social Science (SPSS 20.0 for Windows) software was used to analyze the data.

\section{Results \\ Background Characteristics of Currently Married Women}

Despite a legal minimum age of marriage at 20 , or 18 with parental consent, more than half of women $(55 \%)$ who had participated in the domestic violence module had got married before 18 years. On the other hand, only about a quarter of the women $(24 \%)$ got married at 20 years or above. Almost a quarter of the married women $(24 \%)$ were youth aged 15 24. A considerable proportion of the women (24\%) had four or more children. More than two in five women were illiterate $(42 \%)$ and less than two in five women (39\%) had high autonomy in household decision. More than three in five $(61 \%)$ were working. Almost two in five women (36\%) were from Janajati ethnic background followed by Brahmin/ Chhetri (30\%). An overwhelming majority of the women were Hindu (86\%). More than one fifth of the women $(22 \%)$ had experienced physical violence and about seven percent of women had experienced sexual violence by their husband (Table 1). 
Table 1. Background characteristics of currently married women

\begin{tabular}{|c|c|c|}
\hline Background characteristics & $\%$ & $\mathbf{N}$ \\
\hline \multicolumn{3}{|l|}{ Age at marriage } \\
\hline Less than 15 & 11.4 & 393 \\
\hline $15-17$ & 43.3 & 1492 \\
\hline $18-19$ & 20.9 & 721 \\
\hline 20 and above & 24.4 & 841 \\
\hline \multicolumn{3}{|l|}{ Age group } \\
\hline Less than 25 years & 23.8 & 820 \\
\hline $25-34$ & 37.6 & 1294 \\
\hline 35 or above & 38.7 & 1333 \\
\hline \multicolumn{3}{|l|}{ Total children ever born } \\
\hline None/one & 29.6 & 1020 \\
\hline Two & 28.4 & 978 \\
\hline Three & 17.6 & 606 \\
\hline Four or more & 24.4 & 843 \\
\hline \multicolumn{3}{|l|}{ Education } \\
\hline No education & 41.5 & 1430 \\
\hline Primary & 18.4 & 634 \\
\hline Secondary or above & 40.1 & 1383 \\
\hline \multicolumn{3}{|l|}{ Women's autonomy in household decision } \\
\hline No autonomy & 26.3 & 906 \\
\hline Moderate autonomy (involved in 1-2 issues) & 34.6 & 1193 \\
\hline High autonomy (involved in all 3 issues) & 39.1 & 1348 \\
\hline Currently working & 60.6 & 2090 \\
\hline \multicolumn{3}{|l|}{ Caste/Ethnicity } \\
\hline Brahmin/Chhetri & 30.1 & 1037 \\
\hline Janajati & 35.9 & 1238 \\
\hline Dalit & 13.4 & 463 \\
\hline Other & 20.6 & 710 \\
\hline \multicolumn{3}{|l|}{ Religion } \\
\hline Hindu & 86.3 & 2975 \\
\hline Buddhist & 5.3 & 183 \\
\hline Muslim & 4.9 & 168 \\
\hline Kirat/Christian & 3.5 & 121 \\
\hline \multicolumn{3}{|l|}{ Province } \\
\hline Province 1 & 16.8 & 578 \\
\hline Province 2 & 22.2 & 766 \\
\hline Province 3 & 19.0 & 657 \\
\hline Province 4 & 9.9 & 340 \\
\hline Province 5 & 17.3 & 595 \\
\hline Province 6 & 6.2 & 214 \\
\hline Province 7 & 8.6 & 296 \\
\hline \multicolumn{3}{|l|}{ Place of residence } \\
\hline Urban & 60.1 & 2073 \\
\hline Rural & 39.9 & 1374 \\
\hline \multicolumn{3}{|l|}{ Wealth index } \\
\hline Poor & 37.4 & 1287 \\
\hline Middle & 21.2 & 730 \\
\hline Rich & 41.5 & 1430 \\
\hline Experience of physical violence by husband & 22.1 & 763 \\
\hline Experience of Sexual violence by husband & 6.7 & 231 \\
\hline Total & 100.0 & 3447 \\
\hline
\end{tabular}




\section{Forms of violence}

It was found that a fifth of women $(20 \%)$ were slapped by their husband followed by pushing, shocking or throwing something to them (11\%).
Almost a tenth of the women reported that their husbands kicked or dragged (9\%) and ever had arm twisted or hair pulled (9\%). Similarly, six percent of women reported that their husband physically forced into unwanted sex (Table 2).

Table 2. Experience of physical violence among currently married women by their husband

\begin{tabular}{lcc}
\hline & $\%$ & $\mathrm{~N}=3447$ \\
\hline Ever been slapped by husband & 19.9 & 687 \\
Ever been pushed, shook or had something thrown by husband & 11.3 & 392 \\
Ever been punched with fist or hit by something harmful by husband & 7.8 & 270 \\
Ever been kicked or dragged by husband & 8.7 & 302 \\
Ever been strangled or burnt by husband & 3.4 & 117 \\
Ever been threatened with knife/gun or other weapon by husband & 1.8 & 63 \\
Ever been physically forced into unwanted sex by husband & 6.1 & 212 \\
Ever been forced into other unwanted sexual acts by husband & 2.5 & 88 \\
Ever had arm twisted or hair pulled by husband & 8.8 & 306 \\
Ever been physically forced to perform sexual acts respondent didn't want to & 3.5 & 121 \\
Physical violence by husband (at least one form of physical violence) & $\mathbf{2 2 . 1}$ & $\mathbf{7 6 3}$ \\
\hline
\end{tabular}

\section{Bivariate Analysis}

Child marriage is one of the important factors that had a significant positive effect on increasing physical violence. Experience of physical violence was significantly higher among those who got married at earlier age (experience of physical violence was $34 \%$ among the women who got married before 15 , $25 \%$ among those who got married at 15-17 years and $21 \%$ among those who got married at 18-19 years). Experience of physical violence was lower among those who got married at the age of 20 or above (12\%). Experience of violence was significantly higher among those women who were aged 35 or over $(25 \%)$, who were illiterate $(31 \%)$ and who were from Dalit $(31 \%)$ caste. Similarly, women who followed Muslim religion had significantly higher experience $(34 \%)$ of violence than other religious groups and castes. Likewise, significantly higher percentage of women who lived in province $2(34 \%)$ and rural area (34\%) had experienced more violence. A higher percentage of women form middle wealth family $(27 \%)$ than poor $(24 \%)$ and rich $(18 \%)$ had experienced violence from their husband (Table 3). 
Table 3. Experience of physical violence by their husband according to background characteristics of currently married respondents

\begin{tabular}{|c|c|c|c|c|c|}
\hline \multirow[b]{3}{*}{ Age at marriage } & \multicolumn{3}{|c|}{ Physical violence by husband } & \multicolumn{2}{|c|}{ Total } \\
\hline & No & & Yes & $\%$ & $\mathbf{N}$ \\
\hline & & $* * *$ & & & \\
\hline Less than 15 & 66.5 & & 33.5 & 100.0 & 393 \\
\hline $15-17$ & 74.8 & & 25.2 & 100.0 & 1492 \\
\hline $18-19$ & 78.7 & & 21.3 & 100.0 & 721 \\
\hline 20 and above & 87.8 & & 12.2 & 100.0 & 841 \\
\hline Age group & & $* * *$ & & & \\
\hline Less than 25 years & 83.1 & & 16.9 & 100.0 & 820 \\
\hline $25-34$ & 77.4 & & 22.6 & 100.0 & 1294 \\
\hline 35 or above & 75.1 & & 24.9 & 100.0 & 1333 \\
\hline Total children ever borne & & $* * *$ & & & \\
\hline None/one & 85.9 & & 14.1 & 100.0 & 1020 \\
\hline Two & 79.8 & & 20.2 & 100.0 & 978 \\
\hline Three & 70.0 & & 30.0 & 100.0 & 606 \\
\hline Four or more & 71.4 & & 28.6 & 100.0 & 843 \\
\hline Education & & $* * *$ & & $* * *$ & \\
\hline No education & 69.4 & & 30.6 & 100.0 & 1430 \\
\hline Primary & 76.6 & & 23.4 & 100.0 & 634 \\
\hline Secondary or above & 87.2 & & 12.8 & 100.0 & 1383 \\
\hline Women's autonomy in household decision & & Ns & & & \\
\hline No autonomy & 76.6 & & 23.4 & 100.0 & 906 \\
\hline Moderate autonomy (involved in 1-2 issues) & 79.0 & & 21.0 & 100.0 & 1193 \\
\hline High autonomy (involved in all 3 issues) & 77.7 & & 22.3 & 100.0 & 1348 \\
\hline Currently working & & Ns & & & \\
\hline No & 79.0 & & 21.0 & 100.0 & 1357 \\
\hline Yes & 77.1 & & 22.9 & 100.0 & 2090 \\
\hline Ethnicity & & $* * *$ & & & \\
\hline Brahmin/Chhetri & 88.5 & & 11.5 & 100.0 & 1037 \\
\hline Janajati & 79.7 & & 20.3 & 100.0 & 1238 \\
\hline Dalit & 68.8 & & 31.2 & 100.0 & 463 \\
\hline Other & 65.1 & & 34.9 & 100.0 & 710 \\
\hline Religion & & $* * *$ & & & \\
\hline Hindu & 77.8 & & 22.2 & 100.0 & 2975 \\
\hline Buddhist & 89.4 & & 10.6 & 100.0 & 183 \\
\hline Muslim & 66.5 & & 33.5 & 100.0 & 168 \\
\hline Kirat/Christian & 76.1 & & 23.9 & 100.0 & 121 \\
\hline Province & & $* * *$ & & & \\
\hline Province 1 & 82.7 & & 17.3 & 100.0 & 578 \\
\hline Province 2 & 66.1 & & 33.9 & 100.0 & 766 \\
\hline Province 3 & 79.3 & & 20.7 & 100.0 & 657 \\
\hline Province 4 & 88.1 & & 11.9 & 100.0 & 340 \\
\hline Province 5 & 76.4 & & 23.6 & 100.0 & 595 \\
\hline Province 6 & 85.5 & & 14.5 & 100.0 & 214 \\
\hline Province 7 & 81.1 & & 18.9 & 100.0 & 296 \\
\hline Place of residence & & * & & & \\
\hline Urban & 79.0 & & 21.0 & 100.0 & 2073 \\
\hline Rural & 76.1 & & 23.9 & 100.0 & 1374 \\
\hline Wealth index & & $* * *$ & & & \\
\hline Poor & 76.5 & & 23.5 & 100.0 & 1287 \\
\hline Middle & 72.8 & & 27.2 & 100.0 & 730 \\
\hline Rich & 81.7 & & 18.3 & 100.0 & 1430 \\
\hline Total & 77.9 & & 22.1 & 100.0 & 3447 \\
\hline
\end{tabular}

Note $* * *$ Significant at $\mathrm{p}<0.001 ; * *=\mathrm{p}<0.01$ and $*=\mathrm{p}<0.05$, ns $=$ not significant 


\section{Multivariate Analysis}

Unadjusted and adjusted odds ratios are estimated (Table 4). In first model, only one variable i.e. age at marriage was included to examine the effect of child marriage on women's experience of violence by their husband. Lower age at marriage had increased odds of women experiencing violence by their husband. It was found that women who got married at 18-19 years, 15-17 years and less than 15 years were 1.9 times $(\mathrm{OR}=1.93), 2.4$ times $(\mathrm{OR}=2.41)$ and 3.6 times $(\mathrm{OR}=3.61)$ respectively more likely to experience violence by their husband than those who got married at the age of 20 or later.

In the second model, other individual, family and community characteristics were added to assess the net effect of age at marriage (child marriage) on the dependent variable (i.e., experience of physical violence by husband). After controlling other variables, it was found that women who got married at less than 15 years, 15-17 years, $18-19$ years were 2.3 times (adjusted $\mathrm{OR}=2.33$ ), 1.68 times (adjusted $\mathrm{OR}=1.68$ ) and 1.64 times (adjusted $\mathrm{OR}=1.64$ ) respectively more likely to experience violence by their husbands than those who got married at the age of 20 or later. The slight reduction of the odds ratio of age at marriage in second model indicates that other individual, family and community variables are also important predicators for experiencing violence.
In addition to age at marriage, age of women, education of women, current working status, ethnicity, religion, province, and wealth status were also significant predicators for experiencing violence among women by their husband. Education of women has a negative and statistically significant impact on experiencing violence by their husband. For example, women who had primary and secondary or more education were $23 \%$ and $39 \%$ respectively less likely to experience violence (primary education $\mathrm{aOR}=0.87$ and secondary or above aOR $=0.61$ ) than women who were illiterate. Buddhist women were $61 \%$ less likely $(\mathrm{aOR}=0.39)$ to experience violence from their husband than Hindu women. Similarly, women from rich family were 27 percent less likely ( $\mathrm{aOR}=0.73$ ) to experience violence than poor women. On the other hand, women who were working were more likely to experience violence $(\mathrm{aOR}=1.24)$ than women who were not working. Similarly, women who were from Janajati $(\mathrm{aOR}=2.01)$; Dalit $(\mathrm{aOR}=2.72)$ and other castes $(\mathrm{aOR}=3.16)$ were more likely to experience violence from their husband than women from Brahmin/ Chhetri caste. Women who lived in province 3 were more likely to experience violence from their husband $(\mathrm{aOR}=1.48)$ than women in province 1 . This study did not find significant association between women's autonomy in household decision, urban/rural residence, and experience of violence (Table 4). 
Table 4. Unadjusted and adjusted odds ratio from logistic regression model of experiencing physical violence by individual, households and community characteristics

\begin{tabular}{|c|c|c|c|c|c|c|}
\hline \multirow[b]{2}{*}{ Selected predicators } & \multicolumn{3}{|c|}{ Model I } & \multicolumn{3}{|c|}{ Model II } \\
\hline & $\begin{array}{l}\text { Unadjusted } \\
\text { OR }\end{array}$ & Lower & Upper & $\begin{array}{l}\text { Adjusted } \\
\text { OR }\end{array}$ & Lower & Upper \\
\hline \multicolumn{7}{|l|}{ Age at marriage } \\
\hline Less than 15 & $3.61 * * *$ & 2.69 & 4.84 & $2.33 * * *$ & 1.69 & 3.21 \\
\hline $15-17$ & $2.41 * * *$ & 1.90 & 3.06 & $1.68 * * *$ & 1.29 & 2.18 \\
\hline $18-19$ & $1.93 * * *$ & 1.47 & 2.54 & $1.64 * * *$ & 1.26 & 2.24 \\
\hline 20 and above (reference) & 1.00 & & & 1.00 & & \\
\hline \multicolumn{7}{|l|}{ Age group } \\
\hline Less than 25 years (reference) & & & & 1.00 & & \\
\hline $25-34$ & & & & $1.42 * *$ & 1.11 & 1.84 \\
\hline 35 or above & & & & $1.44 *$ & 1.09 & 1.89 \\
\hline \multicolumn{7}{|l|}{ Education } \\
\hline No education (reference) & & & & 1.00 & & \\
\hline Primary & & & & $0.87 *$ & 0.68 & 0.97 \\
\hline Secondary or above & & & & $0.61 * * *$ & 0.47 & 0.78 \\
\hline \multicolumn{7}{|l|}{$\begin{array}{l}\text { Women's autonomy in household } \\
\text { decision }\end{array}$} \\
\hline No autonomy (reference) & & & & 1.00 & & \\
\hline $\begin{array}{l}\text { Moderate autonomy (involved in 1-2 } \\
\text { issues) }\end{array}$ & & & & 0.98 & 0.78 & 1.22 \\
\hline $\begin{array}{l}\text { High autonomy (involved in all } 3 \\
\text { issues) }\end{array}$ & & & & 0.90 & 0.72 & 1.13 \\
\hline \multicolumn{7}{|l|}{ Currently working } \\
\hline No (reference) & & & & 1.00 & & \\
\hline Yes & & & & $1.24 *$ & 1.03 & 1.49 \\
\hline \multicolumn{7}{|l|}{ Ethnicity } \\
\hline Brahmin/Chhetri (reference) & & & & 1.00 & & \\
\hline Janajati & & & & $2.01 * * *$ & 1.55 & 2.59 \\
\hline Dalit & & & & $2.72 * * *$ & 2.02 & 3.68 \\
\hline Other & & & & $3.16 * * *$ & 2.24 & 4.44 \\
\hline \multicolumn{7}{|l|}{ Religion } \\
\hline Hindu (reference) & & & & 1.00 & & \\
\hline Buddhist & & & & $0.39 * * *$ & 0.23 & 0.65 \\
\hline Muslim & & & & 0.86 & 0.59 & 1.26 \\
\hline Kirat/Christian & & & & 1.06 & 0.67 & 1.67 \\
\hline \multicolumn{7}{|l|}{ Province } \\
\hline Province 1 (reference) & & & & 1.00 & & \\
\hline Province 2 & & & & 1.32 & 0.96 & 1.83 \\
\hline Province 3 & & & & $1.48 *$ & 1.08 & 2.01 \\
\hline Province 4 & & & & 0.67 & 0.45 & 1.02 \\
\hline Province 5 & & & & 1.25 & 0.92 & 1.70 \\
\hline Province 6 & & & & 0.76 & 0.48 & 1.22 \\
\hline Province 7 & & & & 1.09 & 0.74 & 1.63 \\
\hline \multicolumn{7}{|l|}{ Place of residence } \\
\hline Urban (reference) & & & & 1.00 & & \\
\hline Rural & & & & 0.90 & 0.75 & 1.08 \\
\hline \multicolumn{7}{|l|}{ Wealth index } \\
\hline Poor (reference) & & & & 1.00 & & \\
\hline Middle & & & & 0.97 & 0.77 & 1.22 \\
\hline Rich & & & & $0.73 * *$ & 0.58 & 0.91 \\
\hline Constant & & $0.140 * * *$ & & & $982 * * *$ & \\
\hline Cox \& Snell R Square & & 0.026 & & & 0.089 & \\
\hline -2 Log likelihood & & 3556.02 & & & 323.94 & \\
\hline
\end{tabular}

Note $* * *$ Significant at $\mathrm{p}<0.001 ; * *=\mathrm{p}<0.01$ and $*=\mathrm{p}<0.05$ 


\section{Discussion and conclusion}

This study is an effort to examine the prevalence and factors influencing the violence among married women in Nepal. More explicitly, this paper aims to look into whether child marriage (age at marriage) has an impact on women's experience of physical violence by their husband.

This study found that child marriage is widespread in Nepal. This study also found that child marriage is one of the important factors contributing to increase physical violence. Experience of physical violence was found significantly higher among those women who got married at earlier ages (which was found $34 \%$ among women who got married before $15,25 \%$ among those who got married at 15-17 years and $21 \%$ among those who got married at 18-19 years). On the other hand, experience of physical violence was lower among those who got married at the age of 20 or above $(12 \%)$. Multivariate analysis also supported the fact that child marriage increased odds of women experiencing violence by their husband after controlling all the individual, family and community characteristics.

This study found that child marriage has been associated with a higher risk of violence against women. This could be due to the fact that the girls who marry at child age may be more powerless than older married women to defend themselves (Solotaroff and Pande, 2014). The findings are similar to the study conducted in India (Raj et al., 2010; Speizer and Pearson, 2011), Pakistan (Nasrullah et al., 2014) and Bangladesh (Rahman et al., 2014).

The main strength of this study was the use of a nationally representative data set. However, there are some limitations in this investigation. First, because of the cross-sectional design and the nature of the items used in the logistic regression analysis, the study can only provide evidence of statistical association between those items and experience of violence, and this cannot show cause-effect relationships. Secondly, all measures were self-reported. Thus, responses may have been biased by recall errors or intentional misreporting of behavior.

In conclusion, this study found that child marriage is common in Nepal. Although child marriage is a violence in itself, this study also found that child marriage is one of the important factors that had a positive effect on increasing experience of physical violence by their husband. Programmes should focus on creating positive change at the individual and community level around attitudes towards the value of girls in society. This can be done by mobilizing and sensitizing communities and individuals about the harmful effects of child marriage. Programmes should be designed to shift the harmful beliefs around the acceptability of child marriage and other forms of violence.

\section{Acknowledgments}

The author thanks MEASURE DHS + for providing access to the data. Author would also like to thank reviewers who provided their valuable suggestion to improve this manuscript.

\section{REFERENCES}

Bajracharya, A., \& Sajeda, A. (2010). Poverty, gender, and youth: Poverty, marriage timing, and transitions to adulthood in Nepal: A longitudinal analysis using the Nepal living standards survey. Population Council, New York.

Campbell, J.C. (2002). Health consequences of intimate partner violence. Lancet, 359:13311336

Campbell, J.C., Baty, M.L., Ghandour, R.M., Stockman, J.K., Francisco, L., \& Wagman, J. (2008). The intersection of intimate partner violence against women and HIV/AIDS: A 
review. International Journal of Injury Control and Safety Promotion, 15(4):221-31

Clark, S. (2004). Early marriage and HIV risks in sub-Saharan Africa. Stud Family Plann, 35(3):149-60.

De Visser, R.O., Rissel, C.E., Richters, J., \& Smith, A.M.A. (2007). The impact of sexual coercion on psychological, physical, and sexual well being in a representative sample of Australian women. Archives of Sexual Behavior, 36: 676686

Erulkar, A. (2013). Early marriage, marital relations and intimate partner violence in Ethiopia. International Perspectives on Sexual and Reproductive Health, 6-13.

Glynn, J.R., Caraël, M., Auvert, B., Kahindo, M., Chege, J., Musonda, R., Kaona, F., \& Buvé, A. (2001). Study Group on the Heterogeneity of HIV Epidemics in African Cities. Why do young women have a much higher prevalence of HIV than young men? A study in Kisumu, Kenya and Ndola, Zambia. AIDS, 15:S51-60

Hughes, T.L., Johnson, T., \& Wilsnack, S.C. (2001). Sexual assault and alcohol abuse: A comparison of lesbians and heterosexual women. Journal of Substance Abuse, 13, 515-532

ICRW (International Center for Research on Women), and Plan International. (2013). Asia child marriage initiative: Summary of research in Bangladesh, India and Nepal. ICRW and Plan Asia Regional Office.

ICRW. (2011). Delaying marriage for girls in India: A formative research to design interventions for changing norms. ICRW Report to UNICEF (United Nations Children's Fund). Delaying Marriage for Girls in India: A Formative Research to Design Interventions for Changing Norms. ICRW Report to UNICEF (United Nations Children's Fund).

Kiplesund, S., \& Morton, M. (2014). Genderbased violence prevention: Lessons from world bank impact evaluations. In nGender Impact: The World Bank's Gender Impact Evaluation Database. Washington, DC: World Bank;
Available from: http://documents.worldbank. org/curated/en/555731468149 666405/pdf/878 540BRI0enGE0Box385206B00PUBLIC0.pdf. Accessed Jan 2018.

Maharaj, P., \& Munthree, C. (2007). Coerced first sexual intercourse and selected reproductive health outcomes among young women in KwaZulu-Natal, South Africa. Journal of Biosocial Science, 39(23):231-44

Ministry of Health, Nepal; New ERA; \& ICF. (2017). Nepal demographic and health survey 2016. Kathmandu, Nepal: Ministry of Health, Nepal.

Murphy, E., \& Carr, D. (2007). Powerful partners: Adolescent girls' education and delayed childbearing. Washington, DC: Population Reference Bureau.

Najman, J.M., Dunne, M.P., Purdie, D.M., Boyle F.M., \& Coxeter, P.D. (2005). Sexual abuse in childhood and sexual dysfunction in adulthood: An Australian population based study. Archives of Sexual Behavior, 34, 517-526.

Nasrullah, M., Zakar, R., \& Zakar, M.Z. (2014). Child marriage and its associations with controlling behaviors and spousal violence against adolescent and young women in Pakistan. Journal of Adolescent Health. 55: 804-809.

Nour, N.M. (2006). Health consequences of child marriage in Africa. Emerg Infect Dis, 12(11):1644-9.

NPC. (2015). Sustainable development goals 2016-2030. National (Preliminary) Report. Government of Nepal. National Planning Commission.

Oshiro, A., Poudyal, A.K., Poudel, K.C., Jimba, M., \& Hokama, T. (2011). Intimate partner violence among general and urban poor populations in Kathmandu, Nepal. Journal of Interpersonal Violence, 26:2073-2092.

Parsons, J., Edmeades, J., Kes, A., Petroni, S., Sexton, M., \& Wodon, Q. (2015). Economic impacts of child marriage: a review of the literature. Rev Faith Int Affairs 2015;13:12-22. 
Rahman, M., Hoque, A., Mostofa, G., \& Makinoda, S. (2014). Association between adolescent marriage and intimate partner violence: A study of young adult women in Bangladesh. AsiaPacific Journal of Public Health. 26:160-168.

Raj, A., Saggurti, N., Lawrence, D., Balaiah, D., \& Silverman, J.G. (2010). Association between adolescent marriage and marital violence among young adult women in India. International Journal of Gynecology \& Obstetrics, 110:35-39.

Santhya, K.G. (2011). Early marriage and sexual and reproductive health vulnerabilities of young women: A synthesis of recent evidence from developing countries. Current Opinion in Obstetrics and Gynecology. 23:334-339
Solotaroff, J.L., \& Pande, R.P. (2014). Violence against women and girls-Lessons from South Asia. World Bank group

Speizer, I.S., \& Pearson, E. (2011). Association between early marriage and intimate partner violence in India: A focus on youth from Bihar and Rajastha. Journal of Interpersonal Violence, 26:1963-1981.

UNFPA. (2014). Ending child marriage: progress and prospects. New York, NY: United Nations Children's Fund; 2014. Available at: https:// www.unicef.org/media/ files/Child_Marriage Report 717 LR..pdf. Accessed January 14, 2018

UNICEF. (2016). Child protection from violence, exploitation and abuse. https://www.unicef.org/ protection/57929 58008.html 